\section{Nowa \\ Audiofonologia \\ Prace przeglądowe \\ - 20 lat stosowania implantu w Polsce •}

\title{
Technologia implantów ślimakowych
}

\section{Cochlear Implants technology}

\author{
Artur Lorens ${ }^{1,2}$, Henryk Skarżyński ${ }^{1,2}$ \\ ${ }^{1}$ Instytut Fizjologii i Patologii Słuchu, Warszawa, ul. Zgrupowania AK „Kampinos” 1, 01-943 Warszawa \\ ${ }^{2}$ Światowe Centrum Słuchu, ul. Mokra 17, Kajetany, 05-830 Nadarzyn
}

Adres autora: Artur Lorens, Światowe Centrum Słuchu, ul. Mokra 17, Kajetany, 05-830 Nadarzyn; e-mail: a.lorens@ifps.org.pl

\begin{abstract}
Streszczenie
Implant ślimakowy jest pierwszą protezą neuronalną stosowaną z sukcesem w praktyce klinicznej. W Polsce pierwsza operacja wszczepienia implantu ślimakowego została przeprowadzona w 1992 roku. W pracy przedstawiono rozwój technologii systemu implantu ślimakowego, który na przestrzeni ostatnich 20 lat doprowadził do znacznego zwiększenie korzyści słuchowych u pacjentów korzystających z tej metody leczenia.
\end{abstract}

Słowa kluczowe: implant ślimakowy • proteza neuronalna • procesor mowy • strategie kodowania mowy

\begin{abstract}
The Cochlear implant is the most successful of all neural prostheses developed to date. First cochlear implantation in Poland was performed in 1992. The present article provides an overview of remarkable progress which has been made in the design and performance of cochlear implants during the past two decades.
\end{abstract}

Key words: cochlear implant $\bullet$ neural prosthesis $\bullet$ speech processor $\bullet$ speech coding strategies

\begin{abstract}
Wstęp
Implanty słuchowe: ślimakowe są jednym z największych osiągnięć medycyny i techniki. Od czasu pierwszej w Polsce operacji wszczepienia implantu ślimakowego, przeprowadzonej przez prof. Henryk Skarżyńskiego w 1992 roku minęło już 20 lat [Skarżyński i wsp. 1992]. W tym czasie dokonał się gwałtowny rozwój technologii medycznych opartych na stosowaniu implantów ślimakowych. Zasada działania systemów implantu ślimakowego polega na wykorzystaniu stymulacji elektrycznej nerwu słuchowego w celu wywołania wrażeń słuchowych [Lorens i wsp. 1997]. Powstały w ten sposób słuch nazwany został słuchem elektrycznym [Lorens i wsp. 2005]. Stwarza on realną szansę na wejście w świat dźwięków zarówno dzieciom z całkowitą głuchotą, które nie słyszały od urodzenia, jak i osobom, które urodziły się słyszące, ale z różnych przyczyn utraciły słuch, wreszcie może w sposób istotny poprawić rozumienie mowy osobom niedosłyszącym, u których aparaty słuchowe nie przynoszą zadawalających efektów [Lorens i wsp. 2006].
\end{abstract}

System implantu ślimakowego zbudowany jest $\mathrm{z}$ dwóch części: wewnętrznej, wszczepianej operacyjnie, i zewnętrznej, noszonej za uchem. Część wewnętrzna składa się z odbiornika i stymulatora elektrycznego, umieszczonych we wspólnej obudowie, oraz z wiązki elektrod.
Część zewnętrzną stanowi procesor mowy [Skarżyński i wsp. 1992].

\section{Nowe technologie medyczne}

Wprowadzanie nowych technologii medycznych w zakresie implantów ślimakowych wiązało się z przełamywaniem barier i rozwiewaniem wątpliwości dotyczących zastosowania tej metody leczenia i terapii. Wątpliwości i uwagi najczęściej przytaczane w literaturze to m.in. [Levitt, 2008]:

1.Z uwagi na to, że ucho wewnętrzne jest strukturą wysoce złożoną, a mechanizm transformacji energii akustycznej w impulsy neuronalne bardzo skomplikowany, możliwość zastąpienia go kilkoma elektrodami i odtworzenia tym samym wszystkich atrybutów percepcyjnych dźwięku wydawała się znikoma.

2. Uważano, że mowa ludzka jest sygnałem zbyt złożonym, aby z wykorzystaniem stymulacji elektrycznej przekazać - za pośrednictwem nerwu słuchowego - do centralnego układu nerwowego niezbędne informacje o parametrach tego sygnału.

3. Twierdzono, że zmniejszona liczba zakończeń nerwu słuchowego w przypadkach niedosłuchu zmysłowo-nerwowego nie wystarczy, aby zapewnić przepływ koniecznej ilości informacji o sygnale mowy.

4. Zakładano, że dzieci z głuchotą wrodzoną nie są w stanie, z wykorzystaniem stymulacji elektrycznej realizowanej 
przez implant ślimakowy, wykształcić właściwych połączeń nerwowych umożliwiających rozwój mowy.

Z uwagi na powyższe obawy, w pierwszych latach wszczepiania implantów ślimakowych do operacji kwalifikowano jedynie osoby dorosłe $\mathrm{z}$ całkowitą głuchotą lub głębokim niedosłuchem, u których odbiór dźwięków nie był możliwy nawet za pośrednictwem najmocniejszych aparatów słuchowych [Skarżyński i wsp. 1993; 1993a; 1994, 1994a]. Spodziewano się, że nowy słuch elektryczny przywróci u tych pacjentów percepcję dźwięków otoczenia oraz usprawni komunikację, wspomagając odczytywanie mowy z ust [Skarżyński i wsp. 1994b]. Analiza wyników pierwszych pacjentów wykazała jednak, że większość z nich jest w stanie zrozumieć znaczną część wypowiedzi jedynie na drodze słuchowej, bez potrzeby czytania z ust [Skarżyński 1999]. Coraz lepsze wyniki rehabilitacji słuchu i mowy u pacjentów dorosłych przyczyniły się do rozwiania wątpliwości i obaw oraz do rozpoczęcia kwalifikowania dzieci do wszczepienia implantu ślimakowego [Skarżyński i wsp. 1994c]. W kolejnych latach realizacji programów implantów ślimakowych na podstawie wyników uzyskiwanych $\mathrm{u}$ dzieci z głębokim niedosłuchem, korzystających $\mathrm{z}$ aparatów słuchowych potwierdzono, że implantowanie dzieci niesłyszących od urodzenia stwarza warunki do lepszego rozwoju mowy.

\section{Nowe technologie wszczepialnych urządzeń elektronicznych}

Na przestrzeni lat technologia urządzeń elektronicznych stanowiących system implantu ślimakowego uległa ogromnym zmianom [Lorens i wsp. 2005]. Proste urządzenia wzmacniająco-stymulujące przekształciły się w skomplikowane systemy, których konstrukcja oparta jest na zastosowaniu cyfrowych procesorów sygnałowych, i które w sposób złożony oraz coraz bardziej selektywny stymulują elektrycznie zakończenia nerwu słuchowego [Lorens i wsp. 2000; 2001].

Aby spełnić zadanie przekazania wrażeń dźwiękowych drogą elektryczną, system implantu ślimakowego musi realizować następujące funkcje [Wilson i wsp. 2008]:

- odbiór sygnału akustycznego i jego zamiana na sygnał elektryczny,

- przetwarzanie sygnału elektrycznego do postaci umożliwiającej stymulację nerwu ślimakowego w taki sposób, aby powstałe w jej skutek wrażenie słuchowe było w jak największym stopniu adekwatne do odebranego sygnału akustycznego,

- przesłanie przetworzonego sygnału elektrycznego do zakończeń nerwu ślimakowego.

\section{Jednokanałowe implanty ślimakowe}

W pierwszych latach Programu Implantów Ślimakowych w Polsce, prowadzonego pod kierunkiem prof. H. Skarżyńskiego, dostępne były jedynie jednokanałowe implanty analogowe [Skarżyński i wsp. 1993; 1993a]. Powyższe funkcje realizowano za pomocą odpowiedniej zamiany dźwięku na sygnał elektryczny, który podawany był na jedną elektrodę - umieszczaną w okolicach zakończeń nerwu słuchowego [Skarżyński 1994d]. Selektywność częstotliwościowa będąca cechą charakterystyczną słuchu akustycznego nie występuje w przypadku stymulacji elektrycznej prowadzonej za pośrednictwem jednej elektrody [Lorens i wsp. 2001]. Pierwszych kilkudziesięciu dorosłych pacjentów korzystało z implantu jednokanałowego, który zapewniał jedynie odbiór podstawowych wrażeń dźwiękowych. $\mathrm{W}$ jednym przypadku na dwadzieścia umożliwiał on rozumienie mowy, jednakże tylko w ograniczonym stopniu [Szuchnik i wsp. 2000].

\section{Wielokanałowe implanty ślimakowe}

Jedynym sposobem odtworzenia selektywności częstotliwościowej i poprawienia rozumienia mowy było zastosowanie stymulacji wieloelektrodowej (wielokanałowej) [Wilson i wsp. 1988].

Wielokanałowe systemy implantów wprowadzono do Programu Implantów w Polsce w 1994 roku [Skarżyński 1994d; 1995]. Sygnał cyfrowy przetwarzany jest na bodziec elektryczny zgodnie z programem umieszczonym w pamięci procesora sygnałowego (wyspecjalizowanego miniaturowego komputera), realizującym określony algorytm przetwarzania, zwany strategią kodowania mowy [Wilson i wsp. 1988]. Strategia ta wzięła swą nazwę od funkcji, jaką pełni zewnętrzna część systemu implantu, zwana procesorem mowy. W części tej dźwięk jest zamieniany (kodowany) w impulsy elektryczne tak, aby powstałe w nerwie słuchowym - pod wpływem stymulacji - impulsy neuronalne, zawierały informacje o wszystkich dźwiękach mowy. Przetworzony sygnał cyfrowy przesyłany jest przez skórę do implantu w postaci fal radiowych za pośrednictwem części zwanej transmiterem. Transmiter noszony jest na głowie za uchem. Utrzymanie go w prawidłowym położeniu umożliwiają magnesy znajdujące się w implancie oraz w samym transmiterze [Lorens i wsp. 2005].

\section{Miniaturyzacja}

Jedna z ważniejszych zmian, które zaszły w dziedzinie stosowania implantów ślimakowych dotyczy miniaturyzacji elementów elektronicznych wchodzących w skład procesora mowy jak również ograniczenia zużycia energii elektrycznej przez te podzespoły elektroniczne [Wilson i wsp. 2003]. Zmiana ta pozwala na stosowanie zmniejszenie wymiarów procesora mowy jak również stosowanie dużo mniejszych baterii zasilających. W pierwszych stosowanych systemach wielokanałowych, procesor mowy zasilany był bateriami typu AA. Miał on postać dość dużego pudełeczka (procesor pudełkowy), które należało nosić zawsze przy sobie. Dostępne były specjalne pokrowce umożliwiające przymocowanie procesora do paska bądź zawieszenie na szyi [Skarżyński 1994d]. Obecnie procesory mowy do wszystkich typów implantów produkowane są w postaci niewielkiego urządzenia zausznego [Skarżyński i wsp. 2005]. Taka miniaturyzacja jest szczególnie istotna w przypadku małych dzieci, implantowanych przed ukończeniem pierwszego roku życia [Piotrowska i wsp. 2001].

\section{Rozwój nowych strategii kodowania mowy}

Wielkie zmiany zaszły również w strategiach kodowania mowy [Wilson i wsp. 2008]. Analizując powstałe strategie kodowania wyraźnie widać dwa diametralnie różne sposoby podejścia do problemu ograniczonej ilości 


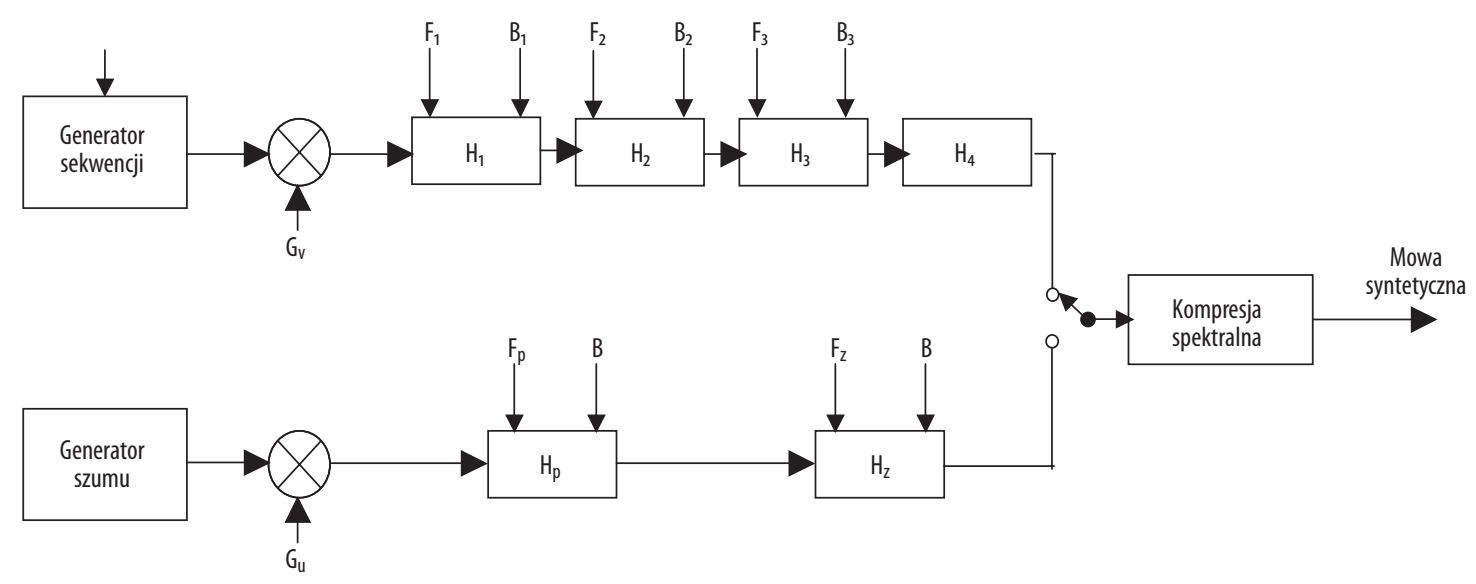

Rycina 1. Schemat blokowy części odbiorczej wokodera formantowego. F1, F2, F3 -częstotliwość pierwszych trzech formantów; B1, B2, B3 - szerokość pierwszych trzech formantów; Fp - częstotliwość rezonansowa dla głosek bezdźwięcznych; Fz częstotliwość antyrezonansowa dla głosek bezdźwięcznych

informacji możliwej do przekazania za pośrednictwem stymulacji elektrycznej, sprowadzające się do stosowania bądź niestosowania wstępnej kompresji objętości sygnału mowy [Wilson i wsp. 1988]. Ilość informacji, która może być odebrana za pośrednictwem stymulacji elektrycznej, jest wielokrotnie mniejsza niż w przypadku słuchu fizjologicznie prawidłowego. Liczba miejsc stymulacji (liczba elektrod) z przyczyn technologicznych i fizjologicznych jest ograniczona i jest ona o wiele rzędów wielkości mniejsza od ilości komórek nerwowych dochodzących do fizjologicznie prawidłowego ślimaka. W klinicznie stosowanych systemach implantów ślimakowych liczba elektrod nie jest większa od 22 [Wilson i wsp. 2008; Skarżyński i wsp. 2005]. Ze względu na wymiary ślimaka i właściwości elektryczne tkanek obszary pobudzenia nerwu prądem przepływającym przez sąsiednie elektrody w zasadzie pokrywają się [Walkowiak i wsp. 2004; 2005]. Zmniejszenie ilości informacji wynika również z ograniczeń w częstości stymulacji, szybkości przetwarzania sygnału przez procesor jak i szybkości transmisji [Wilson i wsp. 1988; Lorens i wsp. 2005]. Strategie kodowania mowy, oparte o założenie konieczności wstępnej kompresji, opracowane zostały zgodnie $\mathrm{z}$ metodą wokoderową. W metodzie wokoderowej przesyła się zbiór parametrów określających sygnał mowy, na podstawie których w odbiorniku dokonuje się syntezy mowy [Tadeusiewicz 1987]. W wokoderach formantowych wysyłanymi parametrami są najczęściej częstotliwości pierwszych trzech formantów F1, F2, F3 oraz ich szerokości B1, B2, B3, w przypadku głosek dźwięcznych, oraz częstotliwości rezonansowe Fp i antyrezonansowe Fz dla głosek bezdźwięcznych. W odbiorniku syntezy mowy dokonuje się przez sumowanie filtrowanego odpowiednio sygnału pobudzenia tonu lub/i szumu (Rycina 1) [Tadeusiewicz 1987].

Koncepcja wokodera formantowego posłużyła do opracowania grup strategii kodowania nazwanych metodami ekstrakcji parametrów dystynktywnych mowy „feature extraction”.. Strategie te wykorzystane zostały w pierwszych systemach wielokanałowych Nucleus, uzywanych w Programie Implantów Ślimakowych od 1994 roku [Skarżyński 1994b]. W historycznie pierwszym algorytmie $\mathrm{z}$ tej grupy koncepcja wokodera pasmowego została uproszczona do wyznaczania częstotliwości tonu krtaniowego F0 oraz częstotliwości i amplitudy drugiego formantu (F2, A2). Następnie udoskonalono algorytm poprzez dodanie informacji o częstotliwości i amplitudzie pierwszego formantu (F1, A1). Dla głosek dźwięcznych sygnały impulsowe o częstotliwości F0 i o amplitudzie proporcjonalnej do A1 i A2 podawane są na elektrody wybrane z danej liczby (w konkretnym zastosowaniu 22), które zgodnie z tonotopowością ślimaka odpowiadają częstotliwościom F1 i F2. Dla głosek szumowych, na jedną wybraną elektrodę przesyłany jest sygnał impulsowy o częstości stochastycznie zmiennej. Uszczegółowiony schemat blokowy praktycznej realizacji algorytmu nazwanego F0F1F2 przedstawiono na Rycinie 2 [McDermott 1992].

Zastosowany algorytm pozwalał części pacjentów na rozumienie mowy, jednakże charakteryzował się szeregiem wad. Rozumienie mowy przez pacjentów zmniejszało się znacząco w obecności sygnału zakłócającego [Clark 1998].

Do strategii realizujących wstępną kompresję zalicza się również strategie o nazwach komercyjnych SPEAK - spectral peak, ACE - advanced combination encoder, dostępne we współcześnie stosowanych systemach implantów Nucleus [McDermott 1992; Szuchnik i wsp. 1997]. W strategiach tych, $\mathrm{z}$ widma sygnału mowy wydziela się pewną liczbę dyskretnych pasm częstotliwości, w których wyznacza się obwiednię amplitudową sygnału. Wyznaczone obwiednie służą do kontroli impulsów prądowych doprowadzanych do odpowiednich elektrod, przyporządkowanych do danego pasma zgodnie $\mathrm{z}$ tonotopią ślimaka [McDermott i wsp. 1992].

Obok prób implementacji algorytmów opartych o metodę wokoderową rozwijała się koncepcja odrzucająca konieczność kompresji objętości sygnału mowy. Zgodnie z nią powstała metoda przetwarzania sygnału na bodziec elektryczny ukierunkowany na dostarczenie do nerwu słuchowego maksimum informacji o sygnale mowy, tzw. metoda CIS (continous interleaved sampling) [Wilson i wsp. 1991]. W metodzie CIS sygnał akustyczny jest, filtrowany przez zestaw filtrów pasmowych dzielących widmo na pasma. Obwiednia sygnałów $\mathrm{z}$ wyjścia filtrów wymnażana jest poprzez 


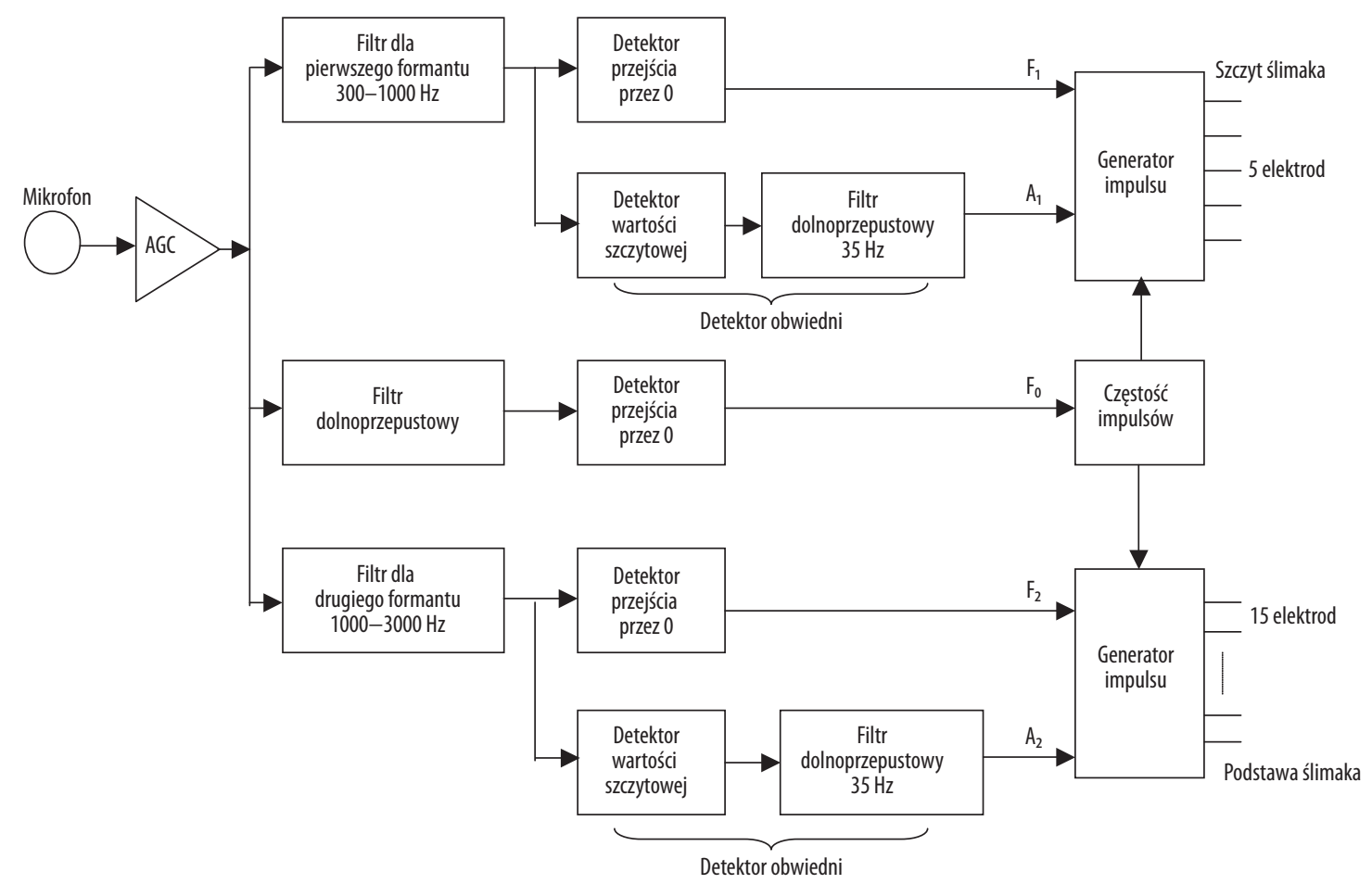

Rycina 2. Schemat blokowy algorytmu FOF1F2.

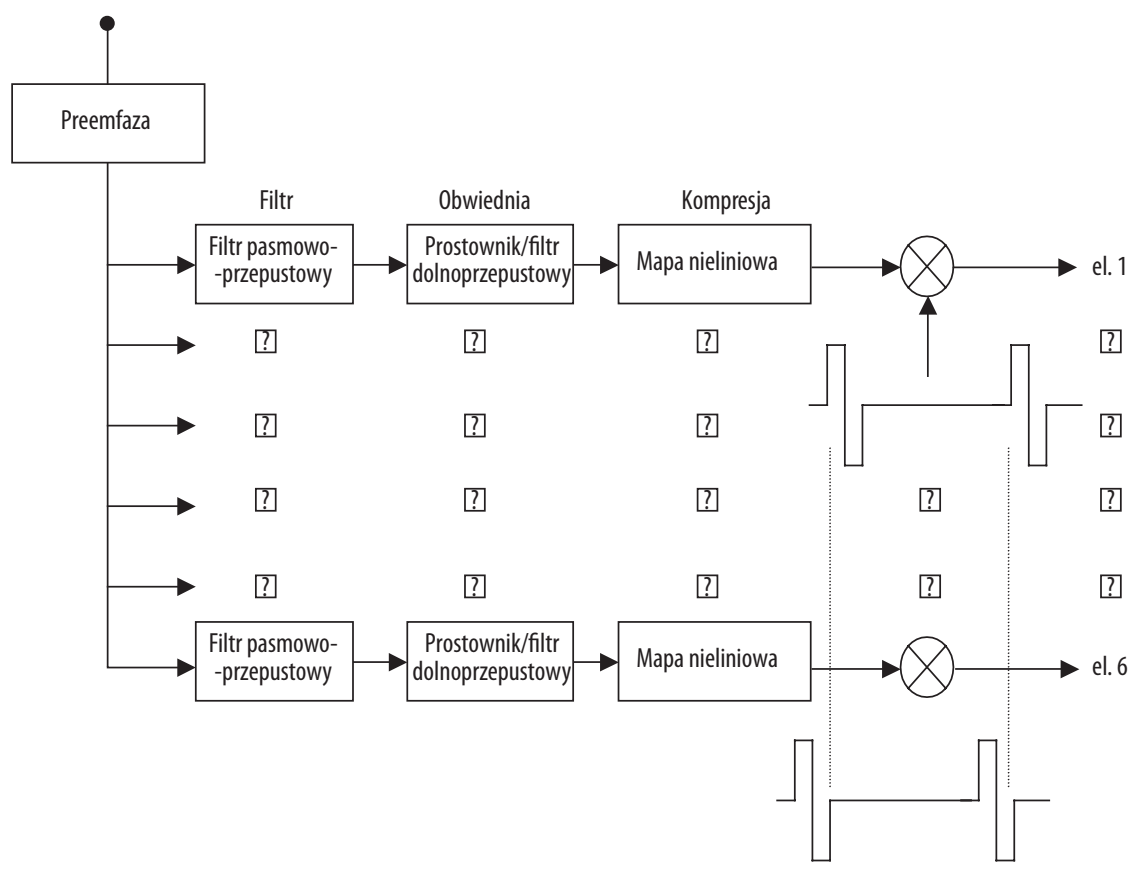

Rycina 3. Metoda „CIS” przetwarzania sygnału akustycznego na bodziec elektryczny.

sygnał impulsowy o odpowiednio dużej częstotliwości. Sygnały impulsowe podawane są na odpowiednią elektrodę przyporządkowaną do odpowiedniego filtru (Rycina 3). Impulsy podawane są kolejno na poszczególne elektrody w taki sposób, aby każdorazowo stymulowane było tylko jedno miejsce w nerwie słuchowym. Ogranicza się w ten sposób powstanie zakłóceń pomiędzy poszczególnymi elektrodami.
Strategia kodowania CIS była po raz pierwszy wykorzystana w wielokanałowych systemach Combi 40 stosowanych od 1994 roku w Programie Implantów Ślimakowych [Skarżyński 1994b]. Pozwalała ona u wielu pacjentów na rozumienie mowy, nawet $\mathrm{w}$ obecności sygnału zakłócającego. Porównując wyniki rozumienia mowy osiągane przez pacjentów w wyniku stosowania na przestrzeni lat 
począwszy od pierwszych prób laboratoryjnych różnych metod, można wyciągnąć wniosek, że metody wykorzystujące filtrację pasmową (CIS, CIS+, HDCIS) wykazują znaczną przewagę w stosunku do metod opartych o wokoder formantowy. Metody oparte o wokoder formantowy zostały obecnie wycofane ze stosowania klinicznego.

Wszystkie stosowane do niedawna strategie kodowania nie zapewniały wystarczającej percepcji struktury czasowej dźwięków. Percepcja struktury czasowej dźwięków jest ważnym zjawiskiem psychoakustycznym, który umożliwia osobom ze słuchem prawidłowym między innymi czerpanie przyjemności ze słuchania muzyki i rozumienie mowy w hałasie. Wprowadzenie ostatnio nowych strategii kodowania FSP (Fine Stucture Processing) ma na celu poprawę odbioru struktury czasowej sygnału przez pacjentów implantowanych. Struktura czasowa sygnału jest kodowana na kilku, (typowo do jednej do czterech) elektrodach najbliższych szczytowi ślimaka poprzez wysyłanie impulsów stymulujących dla ściśle określonej fazy sygnału akustycznego na wyjściu filtru pasmowego przyporządkowanego danej elektrodzie. Wyniki badań klinicznych wskazują, że percepcja struktury czasowej dźwięku realizowana dzięki nowej strategii kodowania FSP zwiększa korzyści z zastosowania systemów implantów ślimakowych [Lorens i wsp. 2010].

Stosowane obecnie w systemach implantów ślimakowych strategie kodowania pozwalają większości pacjentów na swobodną komunikację werbalną, sprzyjających warunkach odsłuchowych, czyli w sytuacji braku dźwięków zakłócających [Lorens i wsp. 2005; 2006]. Mimo, że w trudniejszych warunkach odsłuchowych użytkownicy implantów ślimakowych nadal mają trudności w rozumieniu mowy, to korzyści uzyskane ze współczesnych implantów ślimakowych wskazują na ogromny postęp technologiczny w tej dziedzinie. Stosowane początkowo systemy implantów zapewniały jedynie odbiór dźwięków otoczenia oraz wspomagały odczytywanie mowy z ust [Szuchnik i wsp. 2002; Skarżyński i wsp. 1992].

\section{Podsumowanie}

Wprowadzenie na szeroką skalę wielokanałowych cyfrowych systemów implantów ślimakowych w miejsce jednokanałowych analogowych i opracowanie coraz doskonalszych strategii kodowania mowy otworzyło nowe możliwości stosowania tego typu protezy słuchowej. Bardzo dobre wyniki w rozumieniu mowy uzyskiwane przez znaczną grupę pacjentów implantowanych, tak dorosłych jak i dzieci, pozwalają twierdzić, że implant ślimakowy jest bezpieczną i skuteczną metodą powrotu do świata dźwięku.

Wprowadzenie implantów słuchowych do polskiej praktyki klinicznej 20 lat temu zrewolucjonizowało takie dziedziny medycyny, jak: otolaryngologia, audiologia, foniatria. Pojawiły się wyzwania związane z wczesnym wykrywaniem niedosłuchu, dokładną diagnozą miejsca uszkodzenia drogi słuchowej, opracowaniem nowych technik chirurgicznych, skutecznych metod dopasowania systemów implantów oraz rehabilitacji. Nastąpił również rozwój badań podstawowych z zakresu anatomii, fizjologii, a w szczególności elektrofizjologii słyszenia. Rozwój technik chirurgicznych i mikroelektroniki oraz miniaturyzacja części wszczepialnej implantów ślimakowych przyczyniły się do zmiany kryteriów kwalifikacji. Nowe kryteria dopuszczają implantowanie bardzo małych dzieci oraz pacjentów posiadających czułość słuchu w zakresie niskich częstotliwości i osiągających pewien stopień rozumienia mowy w aparatach słuchowych.

\section{Piśmiennictwo:}

1. Clark G.M.: Research advances for cochlear implants. Auris Nasus Larynx,1998; 25(1): 73-87

2. Levitt H.: Cochlear prostheses: L'enfant terrible of auditory rehabilitation J Rehabil Res Dev, 2008; 45(5): ix-xvi

3. Lorens A., Obrycka A., Geremek A., Skarżyński H.: Analiza wybranych zagadnień dotyczących wykonywania testu elektrostymulacji dla oceny pozaślimakowej drogi słuchowej. Audiofonologia, 1997; XI: 79-88

4. Lorens A., Walkowiak A., Czyżewski A., Skarżyński H.: Psychophysical measurements in cochlear implant patients. Proceedings of $4^{\text {th }}$ European Congress of Oto-Rhino-Laryngology Head and Neck Surgery, I: 131-34 editors: Klaus Jahnke, Markus Fischer, Monduzzi Editore, Italy, 2000

5. Lorens A., Piotrowska A., Walkowiak A. i wsp.:The Psychophysical Measurements of Frequency Selectivity from Cochlear Implanted Patients. Structures-Waves-Biomedical Engineering, 2001; X(2): 79-87

6. Lorens A., Piotrowska A., Skarżyński H., Obrycka A.: Zastosowanie elektronicznych protez wszczepialnych w leczeniu niedosłuchów. Pol Merk Lek, 2005; 19(111): 487-89

7. Lorens A., Skarżyński H., Piotrowska A.: New methods of deafness and partial deafness treatment. Biocybernetics and Biomedical Engineering, 2006; 26: 75-83
8. Lorens A., Zgoda M., Obrycka A., Skarżynski H.: Fine Structure Processing improves speech perception as well as objective and subjective benefits in pediatric MED-EL COMBI 40+ users. Int J Pediatr Otorhinolaryngol, 2010; 74(12): 1372-78

9. McDermott H.J., McKay C.M., Vandali A.E.: A new portable sound processor for the University of Melbourne/Nucleus Limited multielectrode cochlear implant. Acoust Soc Am, 1992; 91(6): 3367-71

10. Piotrowska A., Lorens A., Szuchnik J. i wsp.: Procedura przedoperacyjna kwalifikacji do wszczepienia implantu ślimakowego stosowana w Instytucie Fizjologii i Patologii Słuchu w Warszawie. Audiofonologia, 2001; XX: 43-50

11. Skarżyński H., Janczewski G., Niemczyk K. i wsp.: Wszczepy wewnątrzślimakowe - stan wiedzy, perspektywy, wskazania do stosowania. Otolaryngol Pol, 1992; Supp. 14: 444-51

12. Skarżyński H., Janczewski G., Niemczyk K., Geremek A.: Wybrane problemy w zastosowaniu implantów ślimakowych. Otolaryngol Pol, 1993; 47: 444-51

13. Skarżyński H., Góralówna M., Malesińska M., Geremek A.: I Konferencja Implantów Ślimakowych. Audiofonologia, 1993a; V: $233-36$

14. Skarżyński H., Janczewski G., Góralówna M i wsp.: Wybrane problemy dotyczące programu wszczepów ślimakowych w leczeniu głuchoty. Otolaryngol Pol, 1994; 48(18): 157-60 
15. Skarżyński H.: Wszczep ślimakowy u osoby dorosłej z głuchotą prelingwalną. Otolaryngol Pol, 1994a; 48(15): 152-59

16. Skarżyński H.: Idea implantu ślimakowego. Otolaryngol Pol, 1994b; 48(15): 9-12

17. Skarżyński H., Geremek A., Malesińska M. i wsp.: Wskazania do wszczepów ślimakowych u dzieci. Otolaryngol Pol, 1994c; 48(18): 154-57

18. Skarżyński H.: Wybrane problemy chirurgiczne związane z implantacją wszczepów ślimakowych. Otolaryngol Pol, 1994d; 48(15): 51-56

19. Skarżyński H.: Sprawozdanie z udziału w międzynarodowym sympozjum implantów ślimakowych, mowy i słuchu. Otolaryngol Pol, 1995; 49(5): 499-506

20. Skarżyński H.: Wszczepy ślimakowe - stan obecny i perspektywy. Otolaryngol Pol, 1999; 30, LIII: 45-50

21. Skarżyński H., Lorens A., Piotrowska A.: Wszczepy ślimakowe. Sliwinska-Kowalska M. Audiologia Kliniczna. Łódź. Mediton, 2005

22. Szuchnik J., Lorens A., Skarżyński H.: Możliwość odbioru mowy u pacjentów korzystających z implantów ślimakowych $\mathrm{z}$ różnymi strategiami jej kodowania (MPEAK i SPEAK). Audiofonologia, 1997; XI: 19-26
23. Szuchnik J., Skarżyński H., Geremek A., Lorens A.: Porównanie percepcji słuchowej pacjentów korzystających z jednokanałowych implantów ślimakowych po wszczepieniu implantu wielokanałowego. Audiofonologia, 2000; XVIII: 37-43

24. Tadeusiewicz R.: Sygnał Mowy, Wydawnictwa Komunikacji i Łączności, Warszawa, 1987

25. Walkowiak A., Lorens A., Wąsowski A., Skarżyński H.: Rozkład pobudzenia (Spread of excitation) - nowa metoda oceny funkcjonowania nerwu słuchowego, Audiofonologia, 2004; 26: 99-104

26. Walkowiak A., Czyżewski A., Lorens A. i wsp.: Cochlear nerve assessment by measuring the Spread of Excitation (SoE). Audiofonologia, 2005; Supl 67

27. Wilson B.S., Finley C.C., Farmer J.C. i wsp.: Comparative studies of speech processing strategies for cochlear implants. Laryngoscope, 1988; 98: 1069-77

28. Wilson B.S., Lawson D.T., Müller J.M. i wsp.: Cochlear implants: some likely next steps. Annu Rev Biomed Eng, 2003; 5: 207-49

29. Wilson B., Dorman M.: Cochlear implants: a remarkable past and a brilliant future. Hear Res, 2008; 242(1-2): 3-21

30. Wilson B.S., Finley C.C., Lawson D.T. i wsp.: Better speech recognition with cochlear implants. Nature, 1991; 352: 236-38 